\title{
Identification and analysis of a rare CisAB group
}

\author{
Ziyi He*, Yingming Hu, Siping Cui \\ Department of Transfusion Research, Dongguan Blood Center, Dongguan, Guangdong, 523930, China.
}

Keywords: $\mathrm{ABO}$ subgroup, $\mathrm{Cis} \mathrm{AB}$, gene sequencing

\section{INTRODUCTION}

Incompatible $\mathrm{ABO}$ transfusion can lead to immune hemolytic transfusion reaction. Accordingly, a correct ABO subgroup identification is vital for blood transfusion safety ${ }^{[1]}$. ABO subgroups are often characterized by their abnormal appearances and a weakening or disappearance of antigens or antibodies, resulting in mismatched forward and reverse typing. This is mainly caused by $\mathrm{ABO}$ gene mutations, leading to a decrease in A/B transferase activity. This makes ABO subgroups prone to misidentification, which has an important impact on the safety and efficacy of transfusion. The CisAB group is one of such $\mathrm{ABO}$ subgroups with a complex phenotype, which due to various factors is difficult to determine using routine serological testing. Here, one CisAB group case in the Dongguan Blood Center was identified and reported as follows.

\section{MATERIALS AND METHODS}

\section{Subjects}

A blood donor, male, 22 years old, Han nationality, from Anhui province, working in Dongguan was involved in $\mathrm{ABO}$ group identification at his third blood donation. After forward and reverse ABO group identification were found to be inconsistent, serological analysis and subgroup identification were performed. Nucleotide sequencing analysis and sequence alignment were performed after DNA extraction. This study was approved by the Ethics Committee of the Dongguan Blood Center and all aspects of the study complied with the Declaration of Helsinki.

\section{Reagents and instruments}

Monoclonal antibodies anti-A, B (Lot: 20181210), anti-Al (Lot: 20190220), anti-H (Lot: 2018120), antiAB (Lot: 0ABM087), were all provided by Shanghai Hemo Pharmaceutical \& Biological Co., Ltd (China). Reverse typing reagent were prepared in our laboratory. Nucleic acid detector (Biotek, USA), 9700 PCR amplifier (ABI, USA), and 3130xl sequencing machine (ABI, USA) were used.

\section{Serological detection}

The blood sample (EDTA anticoagulant) was detected for routine $\mathrm{ABO}$ group by the microplate method. If weakened and inconsistent agglutination intensities were detected in forward and reverse typing, an absorb-elusion technology was used to verify the existence of weak A or B antigens.

\section{ABO DNA sequence analysis}

DNA was extracted from $0.5 \mathrm{~mL}$ EDTA anticoagulant whole blood with the TIANamp Blood DNA Kit (Qiangen, Germany). The design of primers, amplification of DNA and analysis of bidirectional sequencing were performed by Zhejiang Blood Center's Transfusion Department ${ }^{[2]}$. Sequence analysis was carried out by Chromas software, and the Al01 sequence was used as the reference for nucleotide inser-

*Correspondence to: Ziyi He, MD, Department of Transfusion Research, Dongguan Blood Center, 19 Ningjiang Road, Humen Town, Dongguan, Guangdong 523006, China. TEL: 0086-769-85152673,E-mail: zyhe_8@163.com.

The authors declared no conflict of interests. 
tion, deletion and mutation. The genotype was determined by referring to the International Blood Group Antigen Gene Mutation Database (BGMUT).

\section{RESULTS}

\section{Blood group serological results}

Serological results showed that A and B antigens were present, but the expressions in forward and reverse typing were inconsistent. There was a weak anti-B in the serum (Table 1), and further absorbelusion tests confirmed the existence of weak B antigen on erythrocytes. The agglutination reaction of erythrocytes to anti-H in this blood donor was higher than that in normal $\mathrm{AB}$ blood donors. The preliminary serological results were $\mathrm{A}_{2} \mathrm{~B}_{3}$ or CisAB.

Table 1 Blood group serological test results

\begin{tabular}{|c|c|c|c|c|c|c|c|c|c|}
\hline \multicolumn{5}{|c|}{ Forward typing } & \multicolumn{3}{|c|}{ Reverse typing } & \multirow{2}{*}{ Control } & \multirow{2}{*}{ Condition } \\
\hline anti-A & anti-Al & anti-B & anti-AB & anti-H & Ac & $\mathrm{Bc}$ & Oc & & \\
\hline $4+$ & - & $1+$ & $4+$ & $4+$ & - & $1+$ & - & - & $\mathrm{nt}$ \\
\hline $4+$ & - & $2+$ & $4+$ & $4+$ & - & $2+{ }^{w}$ & - & - & $4^{\circ} \mathrm{C}$ \\
\hline
\end{tabular}

Note: nt, normal temperature, referring to the room temperature; $\mathrm{Ac} / \mathrm{Bc} / \mathrm{Oc}, \mathrm{A} / \mathrm{B} / \mathrm{O}$ group red blood cell; $\mathrm{w}$, weak.

\section{Sequence analysis of PCR products}

The sample's mutation sites were confirmed by multiple PCR amplification and sequencing, and errors in PCR amplification were excluded. The genotype was identified by direct comparison with the A101 reference sequence. The sample's result was CisAB01/O04. Exon 7 with two nucleotides different from A101, namely: nt467 (C>T) and nt803 (G>C) (Fig. 1).

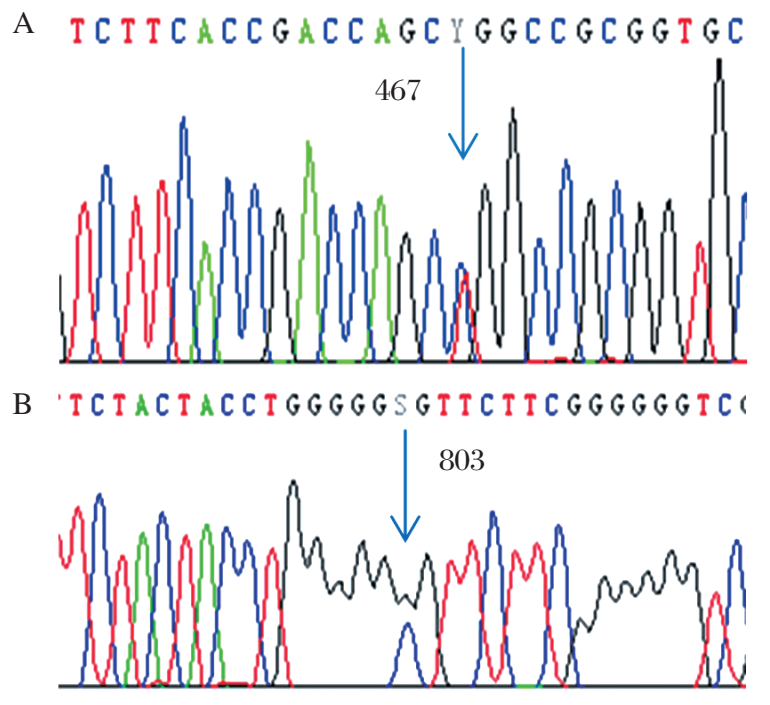

Fig. 1 The mutation sites of gene sequencing.A: $\mathrm{Ar}-$ row points to nt $467(\mathrm{C}>\mathrm{T})$; B: Arrow points to $n t 803(\mathrm{G}>\mathrm{C})$.

\section{DISCUSSION}

Yamamoto et al. reported the $\mathrm{A}_{2} \mathrm{~B}_{3}$ group as displaying weak $\mathrm{A}$ and $\mathrm{B}$ antigens, with $\mathrm{A}$ and $\mathrm{B}$ genes located on the same chromosome ${ }^{[3]}$. CisAB is a unique $\mathrm{ABO}$ phenotype, because its encoded product from the same allele has both A and B specific glycosyltransferase. Meanwhile, CisAB is a relatively rare $\mathrm{ABO}$ subgroup with a very low frequency (about 1 in $160,000 \sim 580,000)^{[4]}$. There are two theories concern- ing the genetic mechanism of $\mathrm{CisAB}$. One suggests that an unequal exchange of chromosomes causes adjacent $\mathrm{A}$ and $\mathrm{B}$ genes to produce independent gene products. The other explains that mutations in A or B genes allow the gene product to become a bifunctionally active enzyme, able to transfer both $\mathrm{N}$-acetylgalactose and galactose to $\mathrm{H}$ receptors ${ }^{[3,5,6]}$. From the literature, the latter is more popular.

The Cis $\mathrm{AB}$ group is under reported in China, due to the lack of further molecular biological analysis. However, a small percentage of samples are confirmed as $\mathrm{ABO}$ subgroups when examined by serological analysis. Common characteristics for CisAB group are the presence of both $\mathrm{A}$ and $\mathrm{B}$ antigens on the membrane of red blood cells, and unexpected antibodies against $B$ antigen in the serum. Additionally, the anti$\mathrm{H}$ reaction is usually positive (4+) and the strength is higher than normal B typing. The antibody titers in serum vary from the different antigenicity in $\mathrm{A} / \mathrm{B} / \mathrm{H}$ antigens. In addition, when detecting irregular antibodies, it is necessary to increase the serum volume or to set the sample at $4^{\circ} \mathrm{C}$ to enhance the response ${ }^{[7]}$. This significantly increases the agglutination strength of reverse typed B cells, better indicating the pre sence of natural anti-B. Compared with the normal AB subgroup, the antigen on CisAB group red blood cells is slightly weaker, while the $\mathrm{B}$ antigen is significantly decreased.

Meanwhile, the distinction between CisAB and $\mathrm{B}$ (A) blood groups should be clarified. The formation mechanism of $\mathrm{B}(\mathrm{A})$ blood group has been reported to be a $\mathrm{B}$ allele point mutation on the basis of the normal B gene sequence, with the mutated B gene able to encode bifunctionally active enzymes. The serology shows not only B antigen specificity, but also weak A antigen specificity. Therefore, a high sensitivity monoclonal anti-A reagent should be used for the detection of $\mathrm{B}(\mathrm{A})$ blood group ${ }^{[8]}$. From the results of 
this sample, $A_{2} B_{X}, A_{X} B, A_{2} B$ and Cis $A B$ groups demonstrated some serological similarities, but there were also many different manifestations. The sequencing found that the sample contained both A and B genes, which made serological testing more complicated. In short, the CisAB subgroup cannot be correctly identified by serological detection alone. Thus, genotyping is necessary to confirm complicated blood groups ${ }^{[9]}$.

It is generally believed that the co-existence of $\mathrm{B}$ antigen and $\mathrm{B}$ antibody in the CisAB group seriously affect the safety and efficacy of transfusion. Clinical blood group identification and crossmatching are often very challenging. Consequently, for patients with the CisAB group, the use of $\mathrm{O}$ blood group for washed red blood cells and $\mathrm{AB}$ blood group plasma is optimal for blood transfusion ${ }^{[10]}$. Owing to the particularity of blood group inheritance, data regarding rare blood groups' incidence and molecular mechanisms in Chinese people have important clinical implications and are worthy of further research in the future.

\section{Acknowledgements}

Thank the Blood Transfusion Department of Zhejiang Blood Center for the technical assistance.

\section{References}

[1] Gradimir M. ABO blood group system[J]. Asia-Pacific Journal of Blood Types and Genes, 2018, 2 (2): 71-84.

[2] Xu XG, Liu Y, Hong XZ, et al. Molecular genetic analy- sis of rare CisAB variants in Chinese population[J]. $\mathrm{He}-$ reditas (Beijing) (in Chinese), 2008, 30(10): 1295-300.

[3] Yamamoto F, McNeill PD, Kominato Y, et al. Molecular genetic analysis of the ABO blood group system: 2 CisAB alleles[J]. Vox Sang, 1993, 64(2): 120-3.

[4] Schenkel-Brunner H. ABO system. Human blood groups chemical and biochemical basis of antigen specificity[M]. 2ed. Wien, New York: Springer, 2000: 145-1477.

[5] Liu YC, Ma L, Zhang DM, et al. The serological and genetic identification of a CisAB blood sample[J]. Chinese Journal of Medical Genetics (in Chinese), 2011, 28(5): 552-4.

[6] Geoff D. Human blood groups [M]. Second Edition. UK, Blackwell Science Ltd a Blackwell Publishing Company, 2002: 39-42.

[7] Xiang D. Detection of ABO subgroup[J]. Chinese Journal of Blood Transfusion (in Chinese), 2010, 23(8): 577-9.

[8] Wu J, Xu XH, Ye HY, et al. Discussions on the genetic characteristics of B (A) blood group and the method of blood transfusion in patients[J]. Chinese Journal of Blood Transfusion (in Chinese), 2010, 23 (11): 951-2.

[9] Li XF, Lin YS, Liu TT, et al. Serological and molecular analysis of $\mathrm{ABO}$ and $\mathrm{Rh}$ blood group chimeras[J]. AsiaPacific Journal of Blood Types and Genes, 2018, 2 (4): 263-8.

[10] Sun CX, Deng G, He YL, et al. Molecular genetic analysis and the expression of erythrocyte antigen of a CisAB01/ A102 genotype[J]. Chinese Journal of Birth Health \& Heredity (in Chinese), 2016, 24 (1): 24-6.

Received 16 December 2019, Revised 21 February 2020, Accepted 13 March 2020 